\title{
Mutinous Colonialism: Navigating Self-Other Dichotomy in Octavia Butler's Survivor
}

\author{
Thamer Amer JubouriAl_Ogaili \\ Faculty of Modern Languages and Communication, Universiti Putra Malaysia \\ Ruzbeh Babaee (Corresponding author) \\ Faculty of Modern Languages and Communication, Universiti Putra Malaysia \\ E-mail: ruzbeh babaei@upm.ed.my
}

Doi:10.7575/aiac.alls.v.6n.4p.166

URL: http://dx.doi.org/10.7575/aiac.alls.v.6n.4p.166
Received: 09/04/2015

Accepted: 10/06/2015

\begin{abstract}
This article examines the self-other relationship in Octavia Butler's novel Survivor (1978). This relationship incarnates the colonial powers brought about the missionaries in their early advent in the fictional place known as "Earth". This place is the foundational setting where the main events take place. The study focuses on the representation of this setting in terms of colonial affiliation. The missionaries are encountered by the natives known as "Kohn" who resist their discrimination practices. Alanna, the protagonist, will be the main focus of the study. She represents the severe dichotomy between the colonial invasion and the proper human attributes. She is a native of Kohn, but she is adopted by the missionaries' leader. Such adoption is highlighted by the use of two main concepts. The first of these is Edward Said's concept of self-other relationship. The second concept is Homi Bhabah's ambivalence. These concepts unravel the suppressed voices in Survivor. They will be analyzed within the colonial infringement in the novel's narrative structure.
\end{abstract}

Keywords: Ambivalence, Postcolonialism, Racial Segregation, Self-Other Relationship

\section{Introduction}

Octavia Bulter's Survivor (1978) circulates the cultural encounters in a seemingly contradiction human visions which "demonstrate the tensions, contradictions, and possibilities of the captivity narrative as a carrier of cultural memory" (Troy, 2010: 1116). The novel polarizes different dimensional human perspectives by which "it forms the basis of, for instance, communal and national belonging and can have a bonding and even normative function" (1116). The normal token of "communal and national belonging" suits the novel's apparent portrayal of diverse human responses to the surrounding changes since "the captivity narrative has generically functioned as spiritual allegory, political propaganda, sensational adventure literature, and ethnological and historical account" (117). Troy's implication of Butler's Survivor concedes the extent to which human relations are restricted by covetous colonial agendas "tensions and contradictions but challenges the colonial and Anglo-American bonding memories and group identities that have found support in captivity narratives" (1118).

Additionally, Survivor integrates Butler critical stances upon contemporary colonial matters and the degenerating oppressive powers; and "from her perspective, postcolonial acknowledges a mere change in government rather than release from the ongoing effects colonial racism" (Thelma, 2006:118). Colonial integration with governmental schedules hinders the national progress in the novel due to Butler's "literary aliens ...demonstrate humanistic characteristics despite their terrifying appearances" (121). In essence, the fictional world of Butler's Survivor" never denying the body as the site of oppression, Butler repeatedly seeks alternatives to the hierarchal tendencies of humanity that have oppressed her gender long before imperialism directed its attention to her race as well" (122). Richard Thelma's propagation of Butler's opposition of colonial ideology lies at the heart of symbolical incarnation between the colonizer and the colonized:"Butler device of travel through time and space by the power of kinship symbolically asserts the impossibility of ending these lines at all” (123).

While the ideological colonialism is the subject of criticism in Survivor, ethnical matter plays a crucial role in constituting the racial boundaries between diverse ethnic groups because "changes in American society, particularly the dynamic between ethnic groups, prompt a reexamination of Butler's early fiction. Survivor (1978) anticipates the challenges contemporary blacks face in an increasingly diverse society" (Anderson, 2006: 35). Additionally, the representation of ethnic groups in interjected colonial powers is the novel's characterization where "Butler uses Alanna, an Afro-Asian protagonist, to illuminate strategies of negotiation for Africans Americans who engage a variety of ethnic groups" (35). The figurative characterization of the protagonist, Alanna, corresponds to Butler's thematic embodiment of the contradictory relationship between ethnical races. The majority of her representational "dynamics" creates new characterization of the oppressed Africans. This characterization is no longer of similar depiction of conventional Black 
and White colonial premises as "Butler's early foray into fiction demonstrates its awareness of similar Afro-Asian Dynamics by meditating on racial dynamics contrary to the traditional black-white racial paradigm" (36).

However, the use of colonial self-other relationship will be highlighted in this study. The study will examine the inherent colonial relationship in Butler's Survivor. The main focus will be on the depiction of the native inhabitants, Kohn, and the missionary experience in the novel's spacial setting. The central theme will be the double cultural encounter between the natives and the alien missionary. This encounter will be studied in the light of the change of the protagonist's, Alanna, native identity and its transformation into a dual predilection. Such predilection encompasses the protagonist's dedication to her native tradition and the new acknowledgment of her adopter's cultural traditions. The study will use two main concepts, Edward Said's self-other relationship and Homi Bhabah's ambivalence.

\section{Self-Other Continuum}

Survivor hinging on a story of human relations tells the story of a group of missionary escaping plague disease to arrive at a land domesticated by natives called Kohn. The central focus of the plot highlights Alanna; the missionary's leader daughter by adoption. She has been adopted by the leader to protect her from destruction at the hands of predominant cultural domination. As Alanna leads a turbulent life, she gets more assimilated with the new culture of missionary people. Yet, she maintains national dedication to her native cultural customs. The amalgamation of her dual cultural experience renders her survival and a stable living.

At the novel's outset, it is relatively acknowledgeable that there is an encounter between two different cultures. However, such encounter does not yield any acknowledgeable setting. Consequently, this cultural encounter takes place in a special void inhabited with strange arrivals and dedicated natives. The whole encounter proceeds over a land, or more specifically, "Earth" as imputed in the first lines; whereby the narrator focalizes the events out of subjective narration with the pronoun "I":"I didn't know enough to appreciate my foster father the way I should have when we met back on Earth. That was when I was about fifteen and his Missionaries caught me stealing from their cornfield" (1). Here, Alanna is the primary narrator who introduces the events in terms of a clash between two fronts. Furthermore, the novel includes a special reclusive denotation of the cultural behavior just from initial recounts of the events. Alanna explicates her dangerous experience during such a clash: "They shot me, would have killed me, but he stopped them. Then he carried me back to his house, got a doctor to tend my wound, and announced that he and his wife were adopting me. Just like that. I heard the doctor try to talk him out of it when they both thought I was unconscious" (1). By depicting this encounter, Butler forges a contiguous opposition between two distinct races, namely, the missionaries and the native Kohn.

In line with this, the appropriation of two cultural oppositions has been asserted in Edward Said's seminal book Orientalism (1979). Said introduces "the vacillation between the familiar and the alien" (72). Said formulates two cultural kinds i.e., "familiar" and "alien" as the relationship between "self" and "other." Any confrontation between two opposite groups could result in a contradictory relationship between these groups. This relationship results in the "validity of the division of races into advanced and backward" (206).

Self-other relationship appears evidently in Survivor. For Example, Alnna considers the missionary's leader her father. In fact he is her foster father but the amalgamation between the two races makes her divided between her Kohn ancestry and the new advents:“and my foster father didn't at first. I don't think he had even before the doctor warned him. All he asked of me was that I learn to put on a good act when I was with people other than him and his wife Neila. That would protect me from the less tolerant of his Missionaries" (1).Alanna is not aware enough of her true ancestory because she is still in the early period colonial missionary: "perhaps during that early period, he was too tolerant himself, though, too willing to let me stand apart from his people as I was naturally inclined to do. Perhaps there was a time when I could have become a Missionary if he had insisted, pushed me" (1-2). Moreover, she contemplates her new paternal state which does not relate to her racial category. Yet, the contact between Kohn and the missionary represents to her one world on their land "Earth": "but as it happened, it was best for him, for his people, and especially for me, that he did not insist. Best that when we left Earth and settled on our new world, I became something else entirely" (2).

The new interconnection between the missionary and Kohn is not equal. In colonial terms, the discrepancy between two distinct groups "has a mission to enlighten, civilize, bring order and democracy, and that it uses force only as a last resort. And, sadder still, there always is a chorus of willing intellectuals to say calming words about benign or altruistic empires" (Said, 1979: 25). Empiral colonialism result in a "discontinuity" between these groups yields contradictory relations "as if one shouldn't trust the evidence of one's eyes watching the destruction and the misery and death brought by the latest mission civilizatrice" (26).Likewise, imperial agenda extends for long extents and"expansionism, and as a loosely microcosmic space in which the dynamics of colonisation are prefigured in a parodic and casual form" (Chrisman, 2003: 28).

In Survivor, the imperial expansion is exposed from the very beginning. When the missionaries arrive in "Earth", they settled as if they will stay for a long time. But throughout their settlement they would live in a permanent "security" away of endangered life: "the Missionaries had transformed their settlement from a scattered collection of cabins almost hidden by the surrounding trees to a solidly stockaded town - a fortress that apparently provided them with the dangerous illusion of security" (2). The missionary not only settle in the Kohn surroundings, but also in the nearby mountains. Alanna is not sure of their malicious advent. Their advent incarnates the colonial invasion of "Earth": "for now, though, she followed them silently as she had for the past two days while they herded their own Tehkohn prisoners down from the mountains" (2).

Imperial colonialism fruits in destructive settlement. This settlement does not affect the colonizer. It mainly affects the colonized territory. The imperial colonialism fits within a special discourse which "has really been lost is a sense of the density and interdependence of human life, which can neither be reduced to a formula nor be brushed aside as 
irrelevant" (Said, 1979:30).Said's polarization of colonial discourse appeals to the self-other relationship. Such kind of discourse has a tremendous formulation of the contrast between two different cultures conforms to a special and common agreement where "the mere repression of colonial memories is never, in itself, tantamount to a surpassing of or emancipation from the uncomfortable realities of the colonial encounter" (Gandhi, 1998: 4).

The groundbreaking agreement between the missionaries and Kohn is the common human sense. Both racial categories appreciate the human attributes of considering the devastating consequences of any bloody clash. The adoption of the missionary's leader for Alanna embodies a human token of human common relations: "they had already reached the foothills and Alanna could look down from the trail into the valley's thick covering of yellow-green meklah trees. For the first time in nearly eight hundred days - two local years - she saw the planet's only settlement of Earth humans. The Mission colony that had once been her home. Like her, it had changed" (2).Alanna, who is a daughter of one of the Kohns, is adopted by one of the foreigners.

Alanna's adoption is a mere contradiction in terms of colonial strategic agendas. In colonial dialectics, there is not balance uniting the colonizer and the colonized relation. Notwithstanding this, there is a comprehensive engagement of this relation through the self-other continuum. The affiliations between the self and the other "dismantle the reductive formulae and the abstract but potent kind of thought that leads the mind away from concrete human history and experience and into the realms of ideological fiction, metaphysical confrontation and collective passion" (Said 34). By the same token, the affinity of the self and the other is not utterly harmonious because "colonial experience is managed without difficulty, as well as with a good deal of disavowal" (Ganguly, 2001:56).

The colonial experience in Survivor comprises both the missionary and Kohn. As a matter of fact, the living of Kohn on "Earth" restores them the right to be the "self". Since the arrival of the missionary takes place on Kohn's land, the proper dichotomy lies in the categorical nomination of the missionary as "other". Kohn does not conquer the missionary. In sharp contrast, the missionaries settle in the land of Kohn and try to incorporate them into their colonial civilization. Just at the first arrival of the missionaries, the clash begins in a consecutive manner to prevent the other (missionary) from conquering Kohn. The Garkohn, or the natives, resist the missionary from the outset of Survivor: "the Garkohn were responsible for involving the Missionaries in this raid that had so endangered them - just as two years before, the Garkohn had made the Missionaries vulnerable by using their settlement as a base from which to raid the Tehkohn. The valley natives were not the friends the Missionaries thought them to be" (5). Here, the ongoing clash between the natives and the missionary undergoes the colonial ambivalence in relation to cultural propinquity.

\section{The Notion of Colonial Ambivalence}

Butler provides us a vivid picture of how the encounter between the missionary and the Kohn has profound influence. Both sides are affected by each other. Alanna's characterization changes according to the "foreigners" ways of life. But the most conspicuous attribute of this influence comes from "mimicry" where Alanna tires to rescue some of the missionaries from the inevitable death. This behavior comes out of loyalty and dedication to her adopter: "the thought of having to go to Natahk now and feign ignorance and friendship sickened her. But for that reason more than any other, she had to do it. She had to let him ask her in carefully veiled words where her loyalties were. What had two years among his enemies done to her?"(5).

Mimicry attributes are dubbed to be an exemplification of colonial ambivalence. In The Location of Culture (1994), HomiBhabah asserts that"the exercise of colonialist authority, however, requires the production of differentiations, individuations, identity effects through which discriminatory practices can map out subject populations that are tarred with the visible and transparent mark of power" (111).Individual "differentiation" springs out of the considerable change in the colonized individuals through the political affairs of colonialism and "its dislocatory presence in order to preserve the authority of its identity in the teleological narratives of historical and political evolutionism" (111).Colonial politics incur unprecedented transformation in the colonized individuality.

To argue this last point, the case of Alanna and her changing identity correlates to the colonial politics in Kohn. She is influenced by the missionaries religion. Additionally, she makes some observations regarding the new religious life through practicing the missionary religiousrituals. The change of her characterized individuality emanates from her devotion to her adopter as a token of cherish. However, she is still not aware of the drastic changes in her tribe and the negative consequences which would happen to the native identity:

The Missionaries had made a religion of maintaining and spreading their own version of humanity - a religion that had helped them to preserve that humanity back on Earth. Now, though, their religion had gotten in their way. It had helped them to justify their belief that the Kohn were lower creatures-higher than apes, but lower than true humans who had been made in the image of God. The trouble was, the Missionaries had known such "intelligent animals" before. Missionary prejudices were long established and, as far as Alanna was concerned, dangerous. If she had accepted them herself, the Tehkohn would have rid her of them. The natives were human enough. (6)

Alanna's gradual change is appraised via the mimicry she makes in following the missionaries. This kind of cultural mimicry embodies a dual relation between the colonized and the colonizer because this "doublethink is made viable only through the strategy of disavowal just described, which requires a theory of the 'hybridization' of discourse and power that is ignored by theorists who engage in the battle for 'power' but do so only as the purists of difference" (Bhabha, 1994: 111). Being so, the colonial "doublelink"consummates cultural advancement since "'progress' and 
'modernity' are set as markers on the paths that peoples and nations walk in the hope that what they seek will redeem the pasts that had such futures in their sights" (Poddar et al., 2008: 1).

In Survivor, Butler offers a reciprocal dual change in the characterization of Alanna. After spending benign experience with the missionaries, she is now able to judge the common good grounds between her traditional customs and the missionary's modernization. In the following example, she has a neutral situation when Diut comes to fight the missionaries. As a rule of thumb, she should fight the colonizers missionaries with Diut; but she does not participate in the fight since she is still dedicated to her adopter. She considers her adoption a human attribute which should not be violated: "it was an admission! Alanna stared down at the table, her expression carefully neutral. Just as she had guessed, Diut had come to see whether the Missionaries were worth the trouble it would cost him to let them live" (55).

Here ambivalent duality emerges as Alanna consecutively aligns the missionaries. This is the intermix of the self and other duality "which marks the emergence of the self and which the self does not control - is concealed by the representation of a placeoutside" (Bhabha, 1994: 146). Hence, ambivalence produces a new human awareness and "its current paramount function as an emerging indicator of the significance of place and a translational cultural identity" (Maver, 2009:25).

Human awareness is a central subject in Survivor. The culmination of this ambivalence exemplifies in the characterization of Alanna. She does not care for her previous traditions relative to Kohn. Instead, she keeps sincere commitment to the missionary. She does not go through the ongoing arguments prevailing "Earth" between the missionaries and Kohn: "there. It was out. Alanna waited for Jules's reaction. It came, explosively, a shouted jumble. Alanna recognized some of the milder arguments. That it was not possible. That the differences between Kohn and human were too great... They were the same arguments that she had repeated to herself when she realized she was carrying Diut's child" (58).As such, Alanna's Traditional state goes along with racial subaltern in terms of female identity.

Alanna's individuality, for example, has undergone drastic changes during the colonial advent of the missionaries. This is the token of self-other relationship which lays the boundaries of racial segregation in colonial circumferences. She has nothing to deal with in her entire life with the missionaries. However, she holds responsible for many things during her previous life in "Earth". Kohn traditional customs inflict heavy domestic requirements on women and their feminine roles in attending family life. But when she lives with the missionaries her domestic role has changed according to the new cultural customs. For example, she does not commit mistakes like Garkohn:

'Tomorrow night,' she began, 'Tehkohn hunters will replace the incoming Garkohn relief guards. They will have to do it near here to prevent Natahk from getting word of it too soon. There's a slight chance that our gate guards might see something - a few luminescent flashes perhaps. If they do, they're to ignore it, and they're to let the Tehkohn hi as though they believe they're admitting Garkohn. Diut has promised that the Tehkohn who take part in this will be disguised-camouflaged-well enough for us defective Missionaries to make an honest mistake. In fact, they'll be disguised well enough for the Garkohn to make the same mistake until the Tehkohn are too close for it to matter. (109)

Alanna's despondent state is touted to the surrounding racial happenings. In Postcolonial Liberalism(2002), Duncan Ivison asserts that segregation bias is a fundamental premise of colonial ambivalence, whereby "liberalism's entanglement with empire, the way indigenous difference has persisted in the face of colonialism, as well as how indigenous peoples have resisted, yet also co-opted and turned around aspects of liberal-democratic thought towards their own ends, we may just catch a glimpse of the possibilities of globalization from the bottom up" (ix). Being so, colonial ambivalence is a manifestation of "indigenous" movement at a micro level. This is because the sense of "the possibilities of globalization" caused by colonial powers. Diasporic movement, in turn, is the interlocution of certain ethnic group in the same national periphery. In Survivor, for example, Natahk displacement embodies the local diaspora of Kohn. He decides to leave Earth because he suffers from the suppressive missionaries: "Natahk was gone. He had made a great show of gathering his fighters - all of them - and leaving the settlement. He had also made a show of shouting his anger at the Missionaries, blaming them for his weapons party's demise" (144).

Furthermore, the suppressed voices of Kohn are not allowed the opportunity to speak. Their identity is more restricted. Here, ambivalence is the identification of the colonized voice. Nevertheless, Alanna is an exceptional case. Buy faces a hindranceexemplified in her female character. She cannot speak even when she lives with the missionaries. She laments her lonely state as the missionaries go fishing and leave her alone: "they're going to keep the fighting as brief and as quiet as possible, and as long as the Missionary guards stay out of the way, they won't be hurt. That's the most important part. Personally, I think the best thing for our people to do is look scared and confused and run for cover" (109).

The treatment of Alanna is not a mere fair hospitalization. There is some sort of racial discrimination played by the missionaries. The issue of racial discrimination is studied in relation to the ambivalence conceptualization of the oppressor (the missionaries).Achille Mbembe, in On The Postcolony (2001), argues that "a great, soft, fantastic body, is seen as powerless, engaged in rampant self-destruction. Human action there is seen as stupid and mad, always proceeding from anything but rational calculation." (8).

Alanna ultimately, recognizes the missionaries 'deceit. She has not been aware of the colonial discrimination brought by the missionary new advent: "it was a mistake. She knew that before the words were out, but she had not been able to 
hold them back. She and Jules glared at each other in open hostility until she spoke again. "You know Diut is a man, as you are a man. Otherwise, how could I have borne his child?" (177).Alanna's deceit harmonizes with Mbembe's argumentation that the colonizer is the source of "every representation of an unstable world [which] cannot automatically be subsumed under the heading "chaos" (parentheses added)" (8).

\section{Conclusion}

Colonial advent has resulted in an immense interference between the original cultural customs in Kohn and the colonial traditional practices. These practices inflict on the native new conceptualization of life and culture. The cultural dimension of the study highlights the mutual discrepancy between the deep-seated traditions and new or foreign traditions. Such traditions have been tackled in terms of geographical encounter initiated on a special setting called "Earth". This setting incarnates a foundational scenario for the cultural confrontation between the missionary and their cultural principles. The portrayal of the natives resulted in a different human perspective. The protagonist - Alanna - has changed dramatically in the light of the colonial powers. She recognizes her transformation state due to colonial affirmation. Colonial destructive impulse has assented contradictory perceptions of colonial reality. Thus, the colonial experience is undergone between two opposite powers, namely, the colonized and the colonizer. These powers are the equilibrium of the disintegration of proper human relations.

The ambivalence analogy between the natives and the new missionaries encompasses the ideological identity by which the colonial traditions hinder, accordingly, the formation of suitable forms of social and cultural life by forging psychological dependence on these substituted images of sovereignty and suppression. Colonial conditions have been a vital subject to the analysis of the contiguous inconsistency through the human encounter's commencement over "Earth".

The racial conceptualization of the colonial world in Survivor circulates the racial practices within the endangered subaltern where females are involved in the process of inferiority. Females also encounter new states of exceptions, whereby racial discrimination provides a comprehensive engagement of females in colonial scenes.

\section{References}

Anderson, C. S. (2006). "the Girl Isn't White": New Racial Dimensions in Octavia Butler's Survivor. Extrapolation (pre-2012) 47(1).

Bhabha, H. K. (1994). The Location of Culture. London: Routledge.

Butler, O. E. (1978). Survivor. Garden City, N.Y: Doubleday.

Chew, Sh. and David R. (2010). A Concise Companion to Postcolonial Literature. Oxford: Blackwell.

Chrisman, L. (2003). Postcolonial Contraventions: Cultural Readings of Race, Imperialism, and Transnationalism. Manchester: Manchester University Press.

Gandhi, L. (1998). Postcolonial Theory: A Critical Introduction. Edinburgh: Edinburgh University Press.

Ganguly, K. (2001). States of Exception: Everyday Life and Postcolonial Identity. Minneapolis: University of Minnesota Press.

Ivison, D. (2002). Postcolonial Liberalism. Cambridge, UK: Cambridge University Press.

Maver, I. (2009). Diasporic Subjectivity and Cultural Brokering in Contemporary Post-Colonial Literatures. Lanham, MD: Lexington Books.

Mbembe, A. (2001).On the Postcolony. Berkeley: University of California Press

Poddar, P., Rajeev S. P., and Lars J. (1979). A Historical Companion to Postcolonial Literatures: Continental Europe and Its Empires. Edinburgh: Edinburgh University Press, 2008. Print.

Said, E. W. (---). Orientalism. New York: Vintage Books.

Thelma, Sh. R. (2006). Defining Kindred: Octavia Butler's Postcolonial Perspective. Obsidian, III( 6/7.2).

Troy, M. H. (2010). Negotiating Genre And Captivity: Octavia Butler's Survivor. Callaloo, 33(4). 